\title{
Estrogenic Regulation of Glia and Neuroinflammation
}

\author{
ANDREA CRESPO-CASTRILLO, MARIA ANGELES AREVALO, \\ LUIS M. GARCIA-SEGURA, AND NATALIA YANGUAS-CASÁS
}

\begin{abstract}
INTRODUCTION
The adult human central nervous system (CNS) has approximately $10^{11}$ cells. Even though all of them derive from a relatively small population of cell precursors in developmental stages, there is a wide variety of cell types in the adult CNS. Cells in the CNS are traditionally classified in two main subtypes: neurons and glial cells. Neurons and most of the glial cells arise from multipotent progenitors that gradually become restricted to the neuronal or glial lineage, except for microglia, which are infiltrating myeloid cells that enter the CNS in the early embryonic stages (Stiles and Jernigan, 2010; Ginhoux and Prinz, 2015).

The importance of neurons for the nervous system is beyond question: they are core components in the CNS and they process and transmit information through neural networks, allowing proper functioning of the system. The role of glial cells, however, has been more controversial. Despite the increasing morphological complexity of glial cells, and the increasing ratio of glia to neurons as one rises through phylogeny, reaching a 10:1 ratio in the human brain, the role of glial cells in higher cognitive functions has not been extensively studied.
\end{abstract}

Often, glial cells have been treated conceptually as of minor relevance in the CNS. They were initially shown to provide neurons with structural support and nutrients and to maintain a suitable homeostatic microenvironment, essential for proper neuronal function and interneuronal communication. However, there is increasing evidence that they play more sophisticated, neuronlike, roles in the CNS.

Glial cells have been assigned several functions in supporting neurons during development and throughout life. Their control of the survival of associated neurons is dependent on prior neuronal triggering of glial cell fate commitment and trophic factor expression. In addition, glial cells control the migration of neurons during development, allowing the proper arrangement of neural networks (Yagi and Sato, 2008). Glial cells and their precursors guide newborn neurons through specific diffusible guidance cues and cellular contacts that lead them to the correct location in the CNS. Moreover, a set of specialized neuroepithelial radial glial cells control the development and lamination of the mammalian neocortex. Radial glia provide a migration scaffold used by roughly $90 \%$ of cortical neurons. There is an analogous process during the migration of newborn neuronal granule cells in the cerebellum along Bergmann glial processes from the internal granule cell layer of the developing postnatal cerebellum. Several lines of evidence indicate that radial glia finally differentiate into astrocytes in the mature brain (Kriegstein and Alvarez-Buylla, 2009).

Glial cells have been shown to modulate the function of neuronal circuits by actively modulating neuronal communication and participating in the integration of systemic signals, such as those that originate in the immune system and the endocrine glands (Araque and Navarrete, 2010). Furthermore, glial cell loss has been shown to contribute to learning and memory impairment (Fields et al., 2014). Therefore, there is increasing interest in understanding their role in neural trophism in physiological conditions and disease.

\section{ROLE OF GLIAL CELLS IN THE REGULATION OF SYNAPTIC FUNCTION}

The mammalian CNS is a very complex network of neural and nonneural cells that allows for both structural and functional complexity. Although electrical signaling is the backbone of brain function, it has been suggested that neurons alone cannot explain complex cognitive processes, especially those involving broad temporal and spatial scales of integration (Fields et al., 2015). It is known that CNS synapses do not exclusively depend on neurons themselves, but also on neuron-glia interactions. Furthermore, 
glial cells far exceed neurons in number, diversity, and functions and can regulate neuronal activity in many ways. Synapse dysfunction precedes the onset of detectable behavioral symptoms in a variety of neurodegenerative diseases (Lepeta et al., 2016). Moreover, the cognitive decline that accompanies several neurodegenerative disorders has been shown to correlate strongly with synapse loss (Morrison and Baxter, 2012). Presumably glial cells play a critical role in controlling the timing, location, number, function, and plasticity of synapses, and perhaps in the evolution of greater synaptic plasticity in the human brain. Therefore, glial modulation of synapse function and number is emerging as a critical component of the role that glia play in the process of neurodegeneration and learning impairment. In consequence, there is increasing interest in the study of how glial cells influence neuronal circuitry and synapses in the developing and adult brain (Eroglu and Barres, 2010; Sierra et al., 2010).

In the following subsections, we will focus on the importance and the specific role of astrocytes, oligodendrocytes, and microglia in the regulation of synaptic function (see Figure 7.1).

\section{Astrocytes}

Astrocytes (star-shaped glial cells) are the most abundant glial cells in the brain. They can be classified into two subtypes, fibrous or protoplasmic, depending on their location and function. Fibrous astrocytes, located in the white matter, have short ramifications with few varicosities and their cell processes establish contact with Ranvier nodes in myelinated fibers and with blood vessels. Protoplasmic astrocytes, on the other hand, are

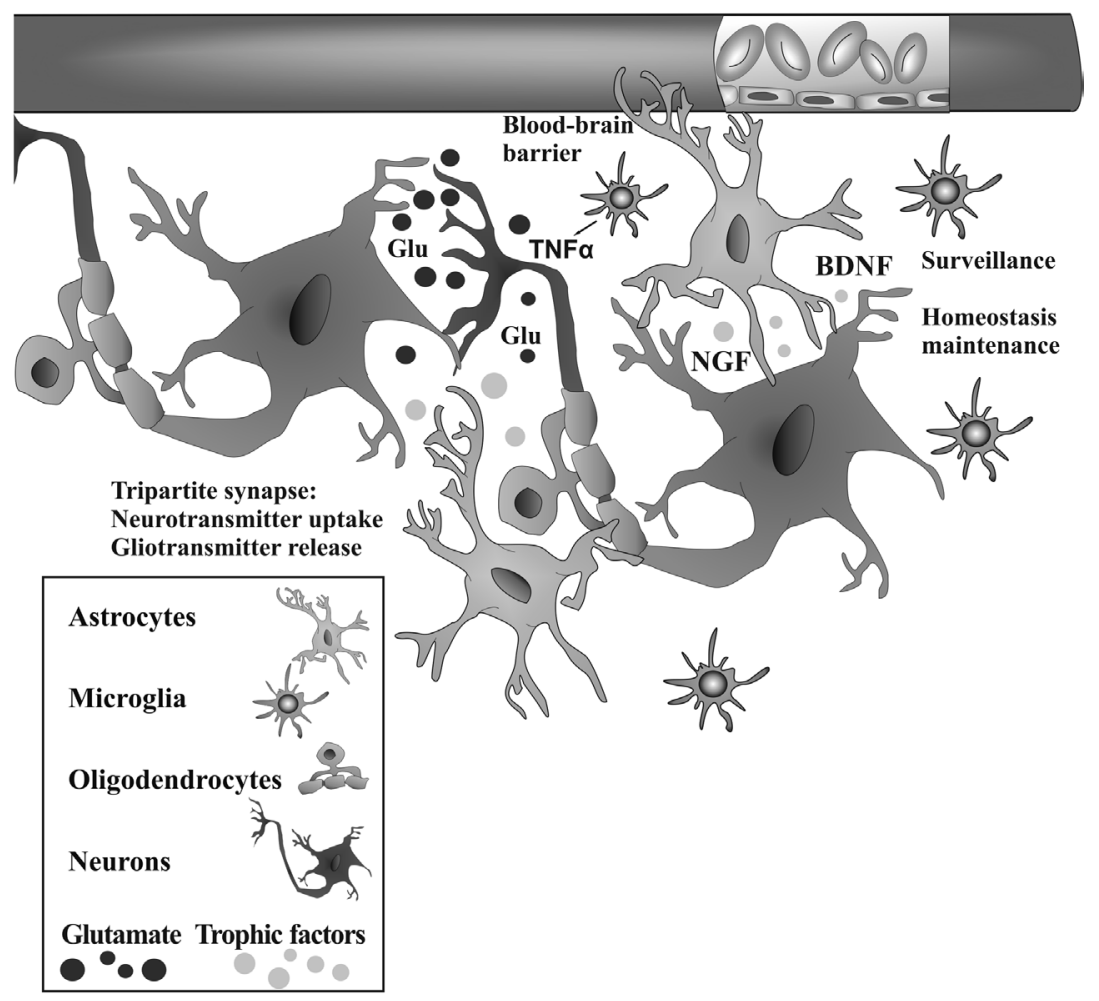

FIGURE 7.1. Synaptic regulation by glial cells under physiological conditions in the central nervous system (CNS). Glial cells actively contribute to an efficient CNS function in physiological conditions. Astrocytes regulate the entrance of nutrients through the blood-brain barrier. They also regulate neural function through the release of trophic factors such as nerve growth factor (NGF) and brain-derived neurotrophic factor (BDNF) and modulate synaptic activity through the uptake of neurotransmitters and the release of gliotransmitters. Oligodendrocytes enable an appropriate neural function through the myelinization of axons and the provision of trophic support for them. Microglia act as sensors of the tissue environment and generate rapid responses against any unbalance in the CNS. Microglia modulate synaptic function and synaptic transmission by releasing different diffusible factors, such as tumor necrosis factor alpha $(\mathrm{TNF} \alpha)$. 
located in the gray matter, where their processes ensheath synapses as well as blood vessels. They have shorter ramifications with plenty of varicosities that are intermingled with dendritic and axonic arborizations and contribute to neuropil complexity (Oberheim et al., 2006). A single astrocyte has thousands of fine processes. The great abundance of ramifications and dilated endings produce the ensheathment of fine blood vessels, dendritic spines and presynaptic buttons (Barres, 2008; Araque and Navarrete, 2010).

Physiologically, astrocytes are involved in the physical structuring of the brain, provide metabolic support to neurons, and are implicated in the maintenance of the blood-brain barrier and in the regulation of the blood flow into the brain. Astrocytes also contact neurons and capillaries and shuttle nutrients between the blood supply and the active neuron. As a single astrocyte can make contacts with multiple neurons, these nonneural cells are also in a good position to mediate the signal transmission that occurs between neighboring neurons (Araque et al., 1999). Ultrastructural examination of the synapse reveals a tripartite structure involving astrocytes, presynaptic terminals, and postsynaptic terminals (Figure 7.1). Astrocytic processes are intimately associated with synapses and literally enwrap the synaptic terminals. This allows the integration of neurotransmitter inputs by astrocytes and triggers the release of their own transmitters, which regulates the activity of neighboring neurons and modulates their function (Halassa et al., 2007). This process is known as gliotransmission and implies a bidirectional signaling pathway between astrocytes and neurons. This selective neurotransmitter release by astrocytes is a fundamental component of their dialogue with neurons during synaptic activity (Halassa and Haydon, 2010; Araque et al., 2014).

Perisynaptic astrocytes are actively implicated in the regulation of neurotransmitter distribution to postsynaptic receptors. They remove the neurotransmitter excess from the synaptic cleft and are also implicated in the regulation of ion concentration in the extracellular space, thereby facilitating efficient synapses. Astrocytes have efficient neurotransmitter recruitment, replacement, and removal systems, preventing redundant effects of neurotransmitters and allowing the postsynaptic neuron to be sensitive to new neurotransmitter waves. Beyond this "resetting" function, astrocytes, through specific transporters (e.g., glutamate transporters), actively remove excitatory neurotransmitters from the synaptic cleft, preventing excitotoxicity and neuronal injury (Ricci et al., 2009; Allen, 2014).
In learning related brain regions, such as the hippocampus, astrocytes contact around $60 \%$ of synapses and also exert cooperative and dynamic motility with their associated dendritic spines in physiological conditions (Haber et al., 2006). On the other hand, astrocyte activation increases miniature inhibitory postsynaptic currents in hippocampal pyramidal neurons. These cells are, therefore, necessary for the activity-dependent modulation of inhibitory synapses in the hippocampus and also play fundamental roles in synapse formation and function (Araque et al., 1999; Bernardinelli et al., 2014). Moreover, they can potentiate synaptic activity through an enhancement of both synapse number and function. Astrocytes can induce synaptogenesis through the release of thrombospondins, which are sufficient to induce fully functional synapses, with normal presynaptic and postsynaptic ultrastructure as well as a proper clustering of presynaptic (e.g., synapsin) and postsynaptic (e.g., postsynaptic density protein 95 [PSD-95]) proteins (Risher and Eroglu, 2012). They have also been shown to induce postsynaptic glutamate responsiveness through a-amino-3-hydroxy5-methyl-4-isoxazolepropionic acid (AMPA) receptors (Chung et al., 2015). Thus, astrocytes are key regulators of synapse formation and function.

In addition, astrocytes constitutively express functional receptors for many different neurotransmitters. Astrocytes are physically connected to each other by gap junctions, generating an electrically coupled (functional) syncytium, which allows rapid transmission and integration of the information among different brain regions through these cells (Fields and StevensGraham, 2002). Hence, neurotransmitter uptake by astrocytes can boost a fast neurotransmittermediated signaling through the entire astrocytic network.

Both gliotransmitter release, and the direct communication between the cytosols of two adjoining astrocytes via gap junction channels, can trigger the appearance of calcium $\left(\mathrm{Ca}^{2+}\right)$ wave transmission in astrocytes. As such, these stimuli work in conjunction to coordinate the activity of a group of cells, inducing an increase in the intracellular $\mathrm{Ca}^{2+}$ transients within astrocytes (Scemes and Giaume, 2006). However, astrocytes can also respond individually to the propagation of $\mathrm{Ca}^{2+}$ waves; that is, they have their own unique response patterns and not all the astrocytes in the brain are activated at the same time (Sofroniew and Vinters, 2010). $\mathrm{Ca}^{2+}$ waves in astrocytes correlate with increased local microvascular blood flow, which is essential for proper homeostasis, 
nutrient intake, and oxygenation of CNS cells. Depending on their specific requirements, neurons can indirectly regulate vasodilatation through the release of neuronal signals that induce glial cells to elevate their $\mathrm{Ca}^{2+}$ levels and to release signals that regulate vasodilatation (Attwell et al., 2010).

However, beyond their role in regulating blood flow, $\mathrm{Ca}^{2+}$ waves are also involved in the regulation of neuronal activity. The neurotransmittermediated induction of $\mathrm{Ca}^{2+}$ waves in astrocytes induces secretion of neuroactive substances from astrocytes back onto synapses (Barres, 2008; Ricci et al., 2009). Elevated $\mathrm{Ca}^{2+}$ levels in astrocytes induce a regulated secretion from secretory lysosomes. These organelles are enriched in certain cell types such as immune cells and glia and play a different role in each specific cell type. In astrocytes they are implicated in the release of adenosine triphosphate (ATP), favoring the propagation of $\mathrm{Ca}^{2+}$ waves between neighboring astrocytes, and a potentiation of the excitatory response (Scemes and Giaume, 2006). Moreover, ATP release by astrocytes regulates CNS synaptic transmission (Araque and Navarrete, 2010). Neurons can control astrocyte activity as well, through the release of substances such as ATP and glutamate. These molecules activate Gprotein coupled receptors in astrocytes, leading to an increase in inositol-3-phosphate (IP3), IP3 receptors, and $\mathrm{Ca}^{2+}$ release from the endoplasmic reticulum, potentiating the calcium wave mediated response (Bazargani and Attwell, 2016).

Astrocytes are the exclusive producers of some transmitters and are implicated in the neuronal neurotransmitter synthesis. Synaptically available D-serine is primarily synthetized and released by astrocytes (Martineau et al., 2014). This neurotransmitter serves as a potent coagonist with glutamate at $N$-methyl-D-aspartic acid or $N$-methyl-D-aspartate (NMDA) receptors, boosting their activation. This neurotransmitter has been described as a potential biomarker for early Alzheimer's disease and is being studied as a potential treatment for schizophrenia (Madeira et al., 2015). Astrocytes are also essential for the de novo synthesis of neuronal glutamate and gamma-aminobutyric acid (GABA), because they serve as primary suppliers of the precursor fourcarbon backbone for these neurotransmitters, which is synthesized in astrocytes by the pyruvate carboxylase enzyme. This synthesis is a regulatory step in the production of glutamate and GABA, and the rate at which astrocytes supply this precursor may limit the rate at which neurons can fire (Schousboe et al., 2014). Astrocytes can also regulate synaptic activity through the synthesis and secretion of many unique lipids, including polyunsaturated fatty acids (PUFAS), whose possible roles at synapses have so far received little attention (Liu et al., 2015).

Recently, there has been a paradigm shift in understanding the extent to which synapse dysfunction and/or loss in neurodegenerative diseases may be mediated by noncell autonomous mechanisms involving astrocytes. Indeed, astrocytic dysfunction, which can lead to glutamate excitotoxicity, has been postulated as a causative agent in synaptic disorders such as Alzheimer's disease and Huntington's disease (Maragakis and Rothstein, 2006). Furthermore, microglial release of proinflammatory agents such as interferon gamma (IFN $\gamma$ ) may induce synapse-enwrapping astrocytes to express the amyloid precursor protein cleaving enzyme $\beta$-secretase (BACE-1), which contributes to amyloid plaque formation in Alzheimer's disease (Rossner et al., 2005). As such, astrocytes may play an important role in the etiology of several neurodegenerative diseases.

\section{Oligodendrocytes}

Oligodendrocytes are the myelin forming cells in the CNS. They have intimate interactions with neurons, providing insulation and trophic support to these cells. Myelinating glia are active participants in CNS function, sculpting the structural and electrical properties of axons by controlling their diameter and spacing, as well as clustering ion channels at nodes and paranodes (Barres, 2008). Beyond these structural functions, there also exists a close and reciprocal relationship essential for neuron-oligodendrocyte survival. Unidentified axon signals are required for the survival of oligodendrocytes, and, reciprocally, demyelinated axons do not survive indefinitely without their myelin, although the mechanisms for this are also unclear (Simons et al., 2014).

Oligodendrocytes are generated from oligodendrocyte precursor cells (OPCs) that migrate from their germinal zones during development and after injury to regions with unmyelinated axons, where they ensheath these axons and then wrap them (Michalski and Kothary, 2015). Moreover, OPCs form their own glutamatergic synapses with axons of neighboring neurons, and express AMPA, kainate, NMDA and metabotropic glutamate receptors (Kolodziejczyk et al., 2010). These synapses between OPCs and surrounding neurons have been hypothesized to provide a means for neuronal activity to modulate oligodendrocyte development. Whenever into fully 
mature oligodendrocytes, synaptic structures are dismantled altogether (De Biase et al., 2010).

Oligodendrocytes are the last cell type to differentiate in the developing brain. Newly differentiated oligodendrocytes ensheath axons through a coordinated process, which is regulated by gamma secretase activity. The inhibition of gamma secretase within oligodendrocytes allows a robust ensheathment of the unmyelinated axon and a coordinated ensheathment of multiple axons by each oligodendrocyte (Ahrendsen and Macklin, 2013). The myelination process also implicates preferentially white-matter-derived astrocytes, particularly in the later stage of wrapping. Neural axons do regulate the myelinating process, as well, through ligand expression. Most ligands have been shown to be inhibitory, such as Jagged (which signals via Notch in OPCs), as well as polysialylatedneural cell adhesion molecule (PSA-NCAM) and leucine-rich repeat and Ig domain-containing Nogo receptor-interacting protein (LINGO-1), which inhibit either OPC differentiation or myelination (Taveggia et al., 2010; Mitew et al., 2014).

Axonal ensheathing by oligodendrocytes increases conduction velocity and clusters ion channels at nodes of Ranvier where action potentials are generated, hence affecting spike timing and oscillations in neuronal activity. Indeed, it is axon myelination that provides rapid impulse propagation for long-range oscillations and synchrony of spike time arrival between distant populations of neurons. Moreover, myelin proteins can also suppress axon sprouting and synaptogenesis, and therefore, myelin has been implicated in synaptic plasticity through the regulation of neuronal network behavior. Evidence suggests that myelin contributes to cognition and learning; changes in white matter structure are associated with different learning tasks, from fine motor learning to language learning (Caroni et al., 2012; Fields et al., 2014, 2015).

Although most OPCs differentiate into myelinating oligodendrocytes, some remain undifferentiated after the completion of myelination, becoming a reservoir of cells with the potential to self-renew, differentiate, and remyelinate the CNS (Leong et al., 2014). In addition to the myelin-forming oligodendrocytes in the mammalian CNS, there are also satellite oligodendrocytes that are considered gray matter and do not play an insulating role. These oligodendrocytes are, therefore, functionally different, due to their perineuronal location, and it has been postulated that they regulate the microenvironment around neurons (Tauheed et al., 2016).

Similar to astrocytes, dysfunction of oligodendrocytes plays a crucial role in some memory-related diseases, such as Alzheimer's disease. For example, they play a direct role via the generation of the toxic isoform of $\beta$-amyloid and the concomitant decrease of some essential proteins for the myelination process, such as myelin basic protein (MBP), proteolipid protein (PLP) and 2',3'-cyclic nucleotide 3' phosphodiesterase (CNP), leading to oligodendrocyte death and neural degeneration (Roth et al., 2005).

\section{Microglia}

Microglia are the resident immune cells in the CNS, and account for $10 \%$ of the glial cells in the human brain and up to $20 \%$ in rodents (Kettenmann et al., 2011). These cells derive from primitive c-kit ${ }^{+}$ erythromyeloid precursors that enter the CNS in early developmental stages, before the neural tube is entirely closed. Despite their mesenchymal origin, microglial cells specialize into a CNS resident population due to their auto-perpetuation and self-renewal, along with the lack of cell replacement by infiltrating cells from the periphery (Ginhoux and Prinz, 2015).

Within the normal brain, microglia appear to act as sensors of the extracellular environment, rapidly responding to and potentially communicating alterations in this environment to surrounding neural cells or non-CNS immune cells. In this way, they can rapidly spread homeostatic information throughout the brain, from one specific area to the surrounding ones and, when necessary, trigger a fast multicellular response to restore homeostasis, implicating several cell types (Harry and Kraft, 2008).

Microglia display at least some phagocytic ability, however, this capacity is not the strong professional phagocytic ability exhibited by activated macrophages. Instead, this limited capacity leads to a fine phagocytic response that is crucial for proper CNS development, adult neurogenesis (Sierra et al., 2010), neuronal wiring, and neural function (Tay et al., 2016).

The role of microglia during CNS development is key. These cells are mediators of the selective elimination of inappropriate synaptic connections during the formation and patterning of mature neural circuits through some immune system molecules, such as the classical complement cascade component 1 (C1q). This component is highly deposited on many synapses throughout the developing CNS. Immature astrocytes release a signal that induces neuronal (and possibly also microglial) expression and secretion of C1q. Secreted C1q binds to and tags developing synapses. Then, at some or all of the synapses, the classical complement cascade becomes activated, 
leading to synaptic deposition of complement component C3 (C3; Schafer et al., 2012; Stephan et al., 2012). Microglia express high levels of C3 receptors and binding of $\mathrm{C} 3$ to this receptor signals microglia (or infiltrating macrophages) to phagocytosis. Microglia phagocytose synaptic terminals of spinal and hypoglossal motor neurons following injury in a process known as synaptic stripping (Gomez-Nicola and Perry, 2015).

Microglia also regulate synaptic function from early embryonic stages, not only through phagocytosis, but also through the release of several mediators. Microglial cells promote synapse generation via the secretion of growth factors during the first wave of embryonic synaptogenesis. Later, during late-stage prenatal and early postnatal development, microglia actively engulf weak synapses through a process called synaptic pruning. In the adult brain, microglia are continuously contacting presynaptic and postsynaptic structures, in an activity dependent manner (Xavier et al., 2014). Even though the microglia-synapse interaction is not entirely understood, some authors postulate a role in synaptic plasticity and experiencedependent rewiring of neural connections, in accordance with neuronal function (Schafer et al., 2012). However, it has been shown that microglia can regulate synapses through the release of mediators, either by promoting synapse formation (e.g., learning-related synapses in the mouse hippocampus through the release of brain-derived neurotrophic factor (BDNF) or by contributing to synapse loss in neurodegenerative diseases (through cytokine release; Wu et al., 2015). Also, microglia respond to a variety of signals from both central and peripheral inflammatory processes, strongly influencing synaptic maintenance and function (e.g., response to complement protein $\mathrm{C} 1 \mathrm{q}$, a mediator of synapse elimination during development and whose concentration is increased in the aging brain) (Kettenmann et al., 2013).

Microglia secreted tumor necrosis factor alpha (TNFa) plays a role in the microglial control of normal function and plasticity of neural circuits. Through the release of this factor, microglial cells can modulate synaptic plasticity, long-term potentiation (LTP) and long-term depression (LTD), thus affecting synaptic activity. This action has been postulated to be mediated through perisynaptic astrocytes, which, unlike neurons, do express TNFa receptors (Ji et al., 2013; Wu et al., 2015).

The phagocytic capacity of microglial cells eliminate debris is essential to maintain tissue homeostasis and avoid secondary neuron damage. Under pathological conditions, prolonged activation of microglia might impair their lysosomal enzymatic complex, limiting the internalization of potentially toxic proteins, such as myelin debris, myelin ovoids and insoluble protein aggregates (Neumann et al., 2009). This dysfunction promotes the pathological alterations in memory-related diseases such as Alzheimer's disease, progressive supranuclear palsy, corticobasal degeneration, and Pick's disease, among others (Ishizawa and Dickson, 2001; Rogers et al., 2007; Majerova et al., 2014).

\section{NEUROINFLAMMATION: IMPLICATIONS FOR LEARNING AND MEMORY}

\section{The Inflammatory Response in the CNS}

Neuroinflammation is an important underlying component of several neurodegenerative diseases. Inflammatory reactions in the CNS differ substantially from those in other tissues in several ways (Xanthos and Sandkuhler, 2014; Heppner et al., 2015). Any inflammatory insult exerts an initial innate immune cell response mainly mediated by macrophages, mast cells, and dendritic cells, which respond after activation in a nonspecific manner to exogenous and endogenous danger signals. This response leads to tissue-specific cell reactions that range from mild responses, which restore homeostasis, to proper inflammatory responses, which drive a full inflammatory response. The latter case involves resident cell activation, vasodilation, and extravasation of plasma components and blood cells to the injury site. This inflammatory response may also involve antigen presentation and the consequent activation of the complement system. The spectrum of the inflammatory response strongly depends on the type, intensity, and duration of the initial triggering signal, the width of the tissue affected area, and the phase of the reaction. Physiological mild controlled inflammatory reactions in the CNS protect neurons from destructive full inflammatory responses. This phenomenon has led to the introduction of the term "neuroinflammation," to distinguish inflammatory reactions in the CNS from that in other tissues.

A chronic or exacerbated neuroinflammatory response is a process that accompanies the progression of several neurodegenerative diseases. Inflammatory responses in the CNS are mediated through a multicomponent immune system that includes both immune (microglia) and nonimmune resident cells (neurons and astrocytes), as well as some immune circulating cells that enter the parenchyma (monocytes, lymphocytes and others). All of these cells contribute to the development and 
outcome of the inflammatory response (Ransohoff and Brown, 2012; Lampron et al., 2013).

Dendritic cells are the professional antigenpresenting cells of the immune system. In their quiescent and mature form, the presentation of self-antigens by dendritic cells leads to tolerance whereas antigen presentation by mature dendritic cells, after stimulation by pathogen-associated molecular patterns, leads to the onset of antigenspecific immunity. In the peripheral tissues, dendritic cells interact with the adaptive immune system, leading to full inflammatory responses, implicating phagocytosis and formation of new connective tissue and granulomas (Sie and Korn, 2017).

Dendritic cells have been found in very specific locations within the CNS in the meninges and circumventricular organs of both healthy and immunologically compromised individuals (D'Agostino et al., 2012). However, in the CNS microglia, astrocytes and, in some regions of the brain, mast cells act as immune cells. The activation of these resident cells is actively depressed under nonpathological conditions, and they rapidly respond to any insult to the CNS. It is perivascular macrophages and vascular pericytes that take over the function of mature dendritic cells, due to their privileged position near the blood vessels (Engelhardt et al., 2016).

Another important difference between the inflammatory response in the CNS, and that of other organs, is the limited permeability of microvessels for the extravasation of large molecules and blood cells due to the blood-CNS barrier. Brain endothelial cells, which are connected by tight junctions, control the flux of soluble factors between the blood and neuronal tissue, while the glia limitans (astrocytic endfeet) are also responsible for limiting the entry of immune cells into the CNS parenchyma in the absence of inflammation (Axtell and Steinman, 2009). This restriction of peripheral cell infiltration into the CNS parenchyma prevents the activation of the complement cascades and the consequent recruitment of the adaptive immune response cells. The "immune privileged tissue" concept in the CNS mostly corresponds to this highly controlled condition of immunological surveillance, the restricted reservoirs where dendritic cells can be found within the steady-state CNS, and the limited entry points for activated leukocytes during neuroinflammation.

Finally, it is worth noting the incorrect assumption that only pathological states induce neuroinflammation. However, neuroinflammation and its mechanisms are not necessarily pathologically driven, and may involve a coordinated immune signaling among immune cells, glial cells, vascular cells, and neurons. Indeed, enhanced levels of neuronal activity can trigger inflammatory reactions in peripheral tissues or locally within the CNS. This phenomenon is known as "neurogenic inflammation" (Xanthos and Sandkuhler, 2014).

\section{Glia and Neuroinflammation}

As we have previously explained, the severely limited infiltration of inflammatory cells from the periphery means that it is mainly resident CNS cells, and specifically glial cells, that deal with infiltrating pathogens, homeostasis disruptions, and tissue damage, as well as generate, regulate, and resolve the neuroinflammatory process in the CNS. The activation of resident cells is accompanied by morphological changes and proinflammatory mediators release in a process called reactive gliosis (see Figure 7.2).

Microglia are the first cell type that respond to a potentially harmful microenvironment and orchestrate the early onset of the inflammatory process after an injury or inflammatory challenge (Kettenmann et al., 2011). They also proliferate and function in tissue repair, including removal of dead tissue and debris through phagocytosis. CNS insults that disrupt homeostasis elicit an acute neuroinflammatory response in these cells that goes along with the release of proinflammatory mediators, causing the activation of surrounding glial cells to counterbalance the changes in tissue homeostasis. Indeed, cytokine release by reactive microglia initiates a cascade of cellular responses that greatly influence astrocytes. During this process, glial fibrillary acidic protein (GFAP) is upregulated in astrocytes (Norden et al., 2016). In a variety of conditions, including neurodegenerative diseases, the GFAP content in the cell body and cell processes increases in astrocytes at the site of injury or activation. These reactive astrocytes repair damaged brain tissue and function in the reestablishment of the integrity of the microenvironment surrounding the lesion (Burda and Sofroniew, 2014).

Reactive microglial cells show enhanced migration to the insult site, as well as increased phagocytic activity and release of inflammatory mediators. If this initial response cannot restore homeostasis, then the inflammatory response is maintained long after the initial insult, turning into chronic neuroinflammation (Amor et al., 2014). The massive cytokine secretion by the resident cells in the CNS leads to changes in the vascular endothelium and glia limitans and, therefore, to a 


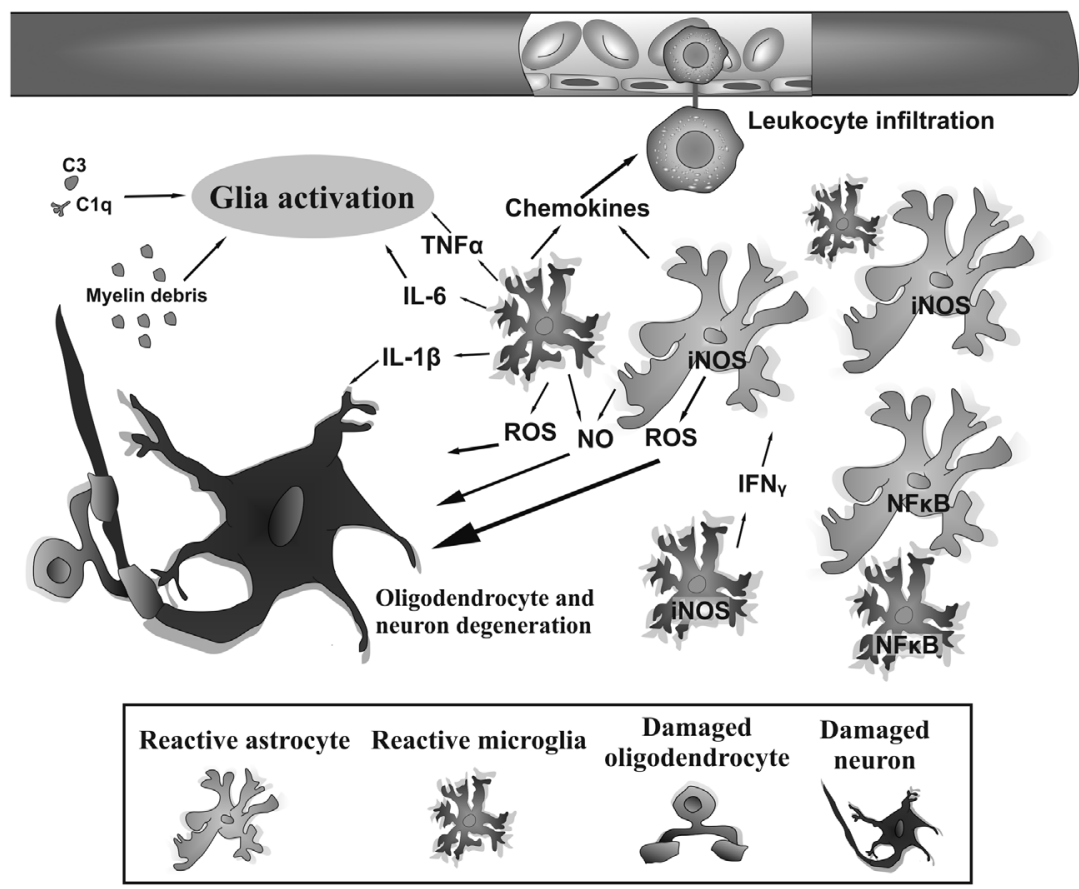

FIGURE 7.2. Glial cells and neuroinflammation. Pathological conditions in the central nervous system (CNS) are usually accompanied by neuroinflammation. This phenomenon leads to the activation of resident glial cells and an increase in the nuclear factor kappa-light-chain-enhancer of activated B cells (NF- $\mathrm{kB}$ ) activation that induces the release of pro-inflammatory mediators by astrocytes and microglia, such as interleukin 1 beta (IL-1 $\beta$ ), interleukin 6 (IL-6), interferon gamma (IFN $\gamma$ ), tumor necrosis factor alpha (TNF $\alpha$ ), nitric oxide (NO), and reactive oxygen species (ROS). These factors generate a positive feedback of the inflammatory response that compromises the blood-brain barrier permeability, allowing a nonselective leukocyte infiltration and the activation of the complement cascade. Several components of this cascade, such as complement cascade component 1 (C1q) and complement component C3 (C3), target synapses for their phagocytosis by microglia or infiltrating macrophages. This multicellular response eventually might lead to oligodendrocyte and neuron degeneration (See color plate).

compromised blood-brain barrier. This situation allows the recruitment of leukocytes and dendritic cells in the perivascular spaces and their transmigration to the CNS parenchyma. An uncontrolled glial activation, the infiltration of leukocytes, and a massive cytokine and chemokine secretion that accompany chronic neuroinflammation are detrimental for the tissue and cause the loss of white and grey matter (Ramesh et al., 2013).

\section{Implications of Neuroinflammation for Learning and Memory}

Neuroinflammation has been linked to several neurological diseases. Interestingly, it has not only been shown to mediate the progression of these disorders, but it is also involved in learning impairment and behavioral diseases from depression to autism (Irwin, 2011; McKim et al., 2016).

Acute or chronic neuroinflammation induce alterations in glial cell function, which switch from a physiological state towards a reactive state. As we have previously mentioned, glial cells are key players for proper synaptic transmission and neuronal activity, and an unregulated glial activation may lead to learning or memory deficits. Indeed, it is the chronic activation of glial cells and consequent cytokine release that impairs these tasks. Elevated cytokine levels in the brain have been shown to mediate sickness behaviors and alter cognitive processes (Dantzer et al., 2008). Moreover, there is a link between memory impairments and increased cytokine expression in humans suffering from multiple sclerosis or Alzheimer's disease (Huijbregts et al., 2004; Guerreiro et al., 2007).

Apart from affecting memory acquisition or consolidation, neuroinflammation may affect cognition by altering activity of specific neural circuits. Indeed, dysregulation of specific neural circuits can occur even during transient neuroinflammation, in the absence of gross 
changes in integrity of gray or white matter (Yaffe et al., 2003; Sparkman and Johnson, 2008; Burton and Johnson, 2012). Moreover, low-level neuroinflammation impairs memory retrieval functions, which can be as disruptive to cognitive function as acquisition or consolidation deficits (Czerniawski and Guzowski, 2014).

Alterations in the function of astrocytes, oligodendrocytes, and microglia, which are key players for proper synaptic transmission and neuronal activity, may lead to learning or memory deficits. Activated microglia may become neurotoxic through their increased expression of proinflammatory cytokines, which lead to extensive neuronal death and disease manifestation. Nitric oxide (NO) release by astrocytes and microglia can also lead to a decrease in ATP, and the consequent energy loss can also induce neuronal dysfunction and cell death (Ricci et al., 2009). Oligodendrocytes are very sensitive to proinflammatory mediators. Inflammatory activated cells and cytokines attack myelin-forming oligodendrocytes and cause their apoptotic cell death. This turns into a poorer myelination of the axons and a compromised synaptic activity.
If there is no oligodendrocyte turnover, its cell death can induce secondary neuronal death.

Increased expression of proinflammatory cytokines such as interleukin-1 $\beta$ (IL-1 $\beta$ ), interleukin-6 (IL-6), and TNF- $\alpha$ disrupts hippocampus-dependent memory tasks in rodents (Pugh et al., 1998; Shaw et al., 2001). Cytokines can, therefore, affect cell signaling pathways and synaptic plasticity and thus, may be responsible for cognitive dysfunction after CNS cell activation in vivo.

Neuroinflammation also leads to a poor modulation of synaptic structure and function. LTP, AMPA receptor trafficking, and neurotransmitter release can all be affected by the actions of proinflammatory cytokines (O'Connor and Coogan, 1999; Albensi and Mattson, 2000; D'Arcangelo et al., 2000; Beattie et al., 2002). Glutamate release by activated astrocytes and microglia leads to synaptic depression and degeneration. An exacerbated release of this neurotransmitter, induced by a poor resolution of neuroinflammation, can drive neuronal dysfunction and excitotoxic neuronal death (Takeuchi et al., 2006; see Table 7.1).

TABLE 7.1. GLIAL CELL ROLES IN PHYSIOLOGICAL AND INFLAMMATORY CONDITIONS IN THE CENTRAL NERVOUS SYSTEM

\begin{tabular}{|c|c|c|c|}
\hline Cell Type & Physiological Functions & $\begin{array}{l}\text { Inflammatory } \\
\text { Environment }\end{array}$ & $\begin{array}{l}\text { Chronic } \\
\text { Neuroinflammation }\end{array}$ \\
\hline Astrocytes & $\begin{array}{l}\text { Physical structuring of the brain } \\
\text { Neuron guidance during } \\
\text { development (radial glia) } \\
\text { Metabolic and trophic } \\
\text { support to neurons } \\
\text { Synapse modulation (neuro- } \\
\text { and gliotransmitter regulation) } \\
\text { Tripartite synapse } \\
\text { Induction of synaptogenesis } \\
\text { Control of the blood-brain barrier }\end{array}$ & $\begin{array}{l}\text { Increase in } \\
\text { proinflammatory } \\
\text { mediators } \\
\text { Reactive oxygen and } \\
\text { nitrogen species } \\
\text { Synapse dysregulation } \\
\text { Compromised } \\
\text { blood-brain barrier }\end{array}$ & $\begin{array}{l}\text { Blood-brain barrier } \\
\quad \text { breakdown } \\
\text { Leukocyte extravasation } \\
\text { Excitotoxicity } \\
\text { Apoptosis }\end{array}$ \\
\hline Oligodendrocytes & $\begin{array}{l}\text { Myelin formation } \\
\text { Axon ensheathment and insulation } \\
\text { Trophic support to neurons } \\
\text { Neuron survival }\end{array}$ & $\begin{array}{l}\text { Oligodendrocyte } \\
\text { degeneration } \\
\text { Myelin debris }\end{array}$ & $\begin{array}{l}\text { Axonal loss } \\
\text { Neuronal degeneration }\end{array}$ \\
\hline Microglia & $\begin{array}{l}\text { Homeostasis surveillance and } \\
\quad \text { maintenance } \\
\text { Synaptic pruning } \\
\text { Promote synaptogenesis } \\
\text { Plasticity of neural circuits }\end{array}$ & $\begin{array}{l}\text { Increase in } \\
\text { proinflammatory } \\
\text { cytokine release } \\
\text { Reactive oxygen and } \\
\text { nitrogen species } \\
\text { Phagocytosis }\end{array}$ & $\begin{array}{l}\text { Tissue damage } \\
\text { Excitotoxicity } \\
\text { Synapse loss (through } \\
\quad \text { cytokine release) }\end{array}$ \\
\hline
\end{tabular}

Note: This table shows changes in glial responses (astrocytes, oligodendrocytes, and microglia) from physiological conditions to chronic neuroinflammation and implications for neuronal function and survival. 
An uncontrolled proinflammatory environment not only impairs learning and memory through neuron death. There is also an increase in the appearance of redundant synapses, both by a decrease in the elimination of weak synapses (synaptic pruning) by microglial cells, and by the upregulation of synapse-inducing genes by astrocytes. These redundant synapses lead to a poor synaptic capacity and the loss of information, which finally leads into impaired memory and learning (Lichtman and Colman, 2000; Holmes, 2001; Groszer et al., 2008; Wang et al., 2011).

\section{ESTRADIOL AND GLIA:}

\section{BACK TO RESTING STATE}

The role of glia in the development of synapse dysfunction and/or synaptic degeneration is clearly a key and potentially targetable component of the pathogenesis in neurological disorders. Due to the crucial role of glial cells in the development of the neuroinflammatory response, the modulation of glia activation has been postulated to represent a potential therapeutic approach for different types of neurodegenerative diseases (Salmina, 2009). The molecular mechanisms that control how and when glia modulate neuronal synaptic structure and function are potential therapeutic targets for preventing eventual neurodegeneration that could develop downstream to synaptic change.
Among the multiple hormonal signals that affect the function of the resident cells in the CNS, special attention has been paid to gonadal steroid hormones. Here, we will focus specifically on the actions of estradiol on glial cells (see Figure 7.3). Glial cells express estrogen receptors and are a direct cellular target for the actions of estradiol in the CNS (Garcia-Ovejero et al., 2005; Arevalo et al., 2012; see Table 7.2). The actions of estradiol on glial cells may impact cognitive processes by modulating the effects of glial cells on synaptic function and by the regulation of neuroinflammation. Indeed, some of the neuroprotective actions of estradiol involve the control of reactive gliosis and the inflammatory response of glial cells, through the upregulation of anti-inflammatory cytokines and the downregulation of proinflammatory mediators. Dysregulation of some immune system molecules accompanies some neurodegenerative diseases. For instance, C1q levels have been demonstrated to be substantially elevated in most acute and chronic CNS diseases, particularly neurodegenerative diseases, which are accompanied by massive synapse loss (Fonseca et al., 2004; Stevens et al., 2007; Perry and O'Connor, 2008; Stephan et al., 2012). A proper regulation of these immune response by estradiol could prevent this synapse loss (Straub, 2007; Vegeto et al., 2008).

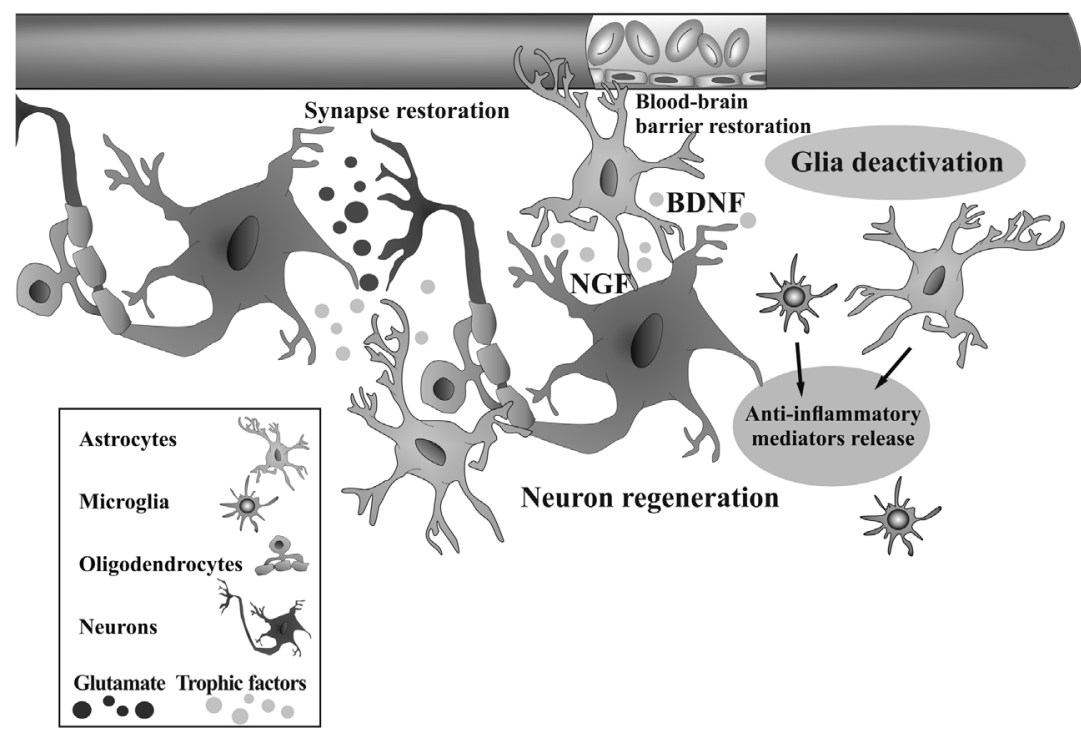

FIGURE 7.3. Neuroprotective actions of estradiol mediated by glial cells. Estradiol modulates neuroinflammation through the deactivation of glial cells and the stimulation of the release of anti-inflammatory mediators by astrocytes and microglia. Estrogens also promote axon remyelination by oligodendrocytes and the release of neurotrophic factors, such as brain-derived neurotrophic factor (BDNF) and nerve growth factor (NGF), by astrocytes, contributing to the restoration of neural and synaptic activity and the restoration of the blood-brain barrier. 
TABLE 7.2. ANTI-INFLAMMATORY ACTIONS OF ESTROGENS ON GLIAL CELLS

\begin{tabular}{lll}
\hline Cell Type & Estrogen Receptor Expression & \multicolumn{1}{c}{ Estrogen Actions } \\
\hline Astrocytes & ERa & Downregulation of proinflammatory cytokine release \\
ER $\beta$ & Increased release of growth factors \\
& Increased glutamate uptake \\
& ERa & Decreased astrogliosis \\
ER $\beta$ & Decreased oxidative stress \\
GPR30/GPER & Prevent axonal loss and to avoid neuronal degeneration \\
& Increased myelination \\
& Increased OPC proliferation \\
& Increased OPC differentiation \\
& Anti-apoptotic effects for mature oligodendrocytes. \\
& ERa & Cell survival \\
ER $\beta$ & Increased anti-inflammatory mediators release \\
GPR30/GPER & Downregulation of proinflammatory cytokine release \\
& Downregulation of activation \\
& Increase in phagocytic capacity \\
& Neuroprotection \\
& Decreased microgliosis \\
& Decreased oxidative stress \\
&
\end{tabular}

Notes: Specific actions of estrogens and estrogen receptor expression on astrocytes, oligodendrocytes and microglia. ER $\alpha=$ estrogen receptor alpha; ER $\beta=$ estrogen receptor beta; GPR30/GPER $=\mathrm{G}$ protein-coupled receptor 30/G protein-coupled estrogen receptor 1 . OPC $=$ oligodendrocyte precursor cell.

The expression of estrogen receptors in glial cells differs from one cell type to another, leading to a specific response of each glial cell type to estradiol. As we have previously mentioned, glial cells are the first to respond to any potential injury in the CNS, through a fast and proportional activation and consequent release of pro- and antiinflammatory mediators. Neuroinflammation is a physiological process that is required to detect and fight any potential threat to the CNS, thus, a proper modulation and resolution of this process is essential to prevent further damages and irreversible injury into the CNS. Indeed, chronic neuroinflammation is a hallmark of several neurodegenerative diseases (Glass et al., 2010; Chen et al., 2016). Proper resolution of the neuroinflammatory process is essential to restore tissue homeostasis and prevent the occurrence of chronic neuroinflammation. Because glial cells are key regulators of the progression and outcome of neuroinflammation, their modulation by estradiol and estrogenic compounds has a great therapeutic potential to control the progression of several neurological diseases (Vegeto et al., 2008; Arevalo et al., 2012). Moreover, estradiol-induced regulation of inflammatory process might be implicated, at least in part, in sex differences associated with the age of onset and/or severity, incidence, and prevalence of neurological diseases, where some are more common in men (Parkinson's disease, autism, schizophrenia) and others in women (multiple sclerosis, Alzheimer's disease, depression; Ober et al., 2008).

In the next subsections, we discuss the specific regulatory effects of estradiol on each glial cell type.

\section{Actions of Estradiol on Astrocytes}

Actions of estradiol on astrocytes are involved in the synaptic actions of this hormone. For instance, estradiol increases the expression of GFAP and the morphology of astrocytes in different brain regions, including the hippocampus, and this affects the interaction of astrocytic processes with synapses (Acaz-Fonseca et al., 2014). In addition, estradiol regulates intracellular $\mathrm{Ca}^{2+}$ levels in astrocytes, inducing a rapid release of intracellular stores of $\mathrm{Ca}^{2+}$, hence increasing rapidly free cytoplasmic $\mathrm{Ca}^{2+}$ concentrations (Chaban et al., 2004; Arnold et al., 2005; Micevych et al., 2010), resulting in an enhancement in neuronal excitability. Estradiol may also affect synaptic function by increasing glutamate uptake by astrocytes through the overexpression of glutamate transporter 1 (GLT1) and glutamate aspartate transporter (GLAST). Astrocytes are also involved in the actions of estradiol in the formation of dendritic spines. For instance, in the preoptic area 
estradiol induces the expression of cyclooxygenase 2 (COX-2) in neurons, which increases the synthesis of prostaglandin E2 (PGE2). PGE2 released by neurons, induces the release of glutamate by astrocytes, which in turn promotes the formation of new dendritic spines (Wright et al., 2010).

As previously mentioned, in response to tissue damage, astrocytes undergo a well described sequence of morphological changes including the acquisition of a larger soma and shorter prolongations, up to a filamentous-like appearance. In this activation stage contact inhibition is entirely lost, and reactive astrocytes aggregate around the insulted area. The morphological changes are accompanied by the secretion of inflammatory mediators, which serve to potentiate and spread the inflammatory response through the CNS. Apart from the chemokine and cytokine mediated response, astrocytes also spread calcium waves from the injured site to peripheral areas both through cell-cell gap junctions and the release of ions to the extracellular space. Estradiol reduces astrogliosis after different forms of brain injury and reduces the release by astrocytes of proinflammatory molecules, such as IL-1 $\beta$, IL-6, $\mathrm{TNF} \alpha$, matrix metalloproteinase 9 (MMP-9), and IFN- $\gamma$-inducible protein 10 (IP-10; Acaz-Fonseca et al., 2016).

Interestingly, reactive astrocytes express the enzyme aromatase, which catalyzes the synthesis of estradiol (Garcia-Segura et al., 1999). The de novo induction of aromatase expression by reactive astrocytes leads to an increased production of estradiol in injured areas in the brain (Saldanha et al., 2009). Local estradiol production by reactive astrocytes is also accompanied by the upregulation of estrogen receptor alpha (ER $\alpha)$ and beta $(\operatorname{ER} \beta)$ in these cells. This probably enhances the production of neurotrophic factors by reactive astrocytes in response to estradiol (Garcia-Segura et al., 1999).

Estradiol exerts a direct action on astrocytes through both ER $\alpha$ and ER $\beta$ (see Figure 7.4A). Even though astrocytes do express both receptors, the anti-inflammatory effects of estrogens on these cells in vivo has been postulated to be mediated mostly through ERa (Spence et al., 2013). Interestingly, in vitro inflammation models have shown that the anti-inflammatory effect of estradiol is produced through ER $\beta$. Thus, the importance of this receptor in the estrogenic regulation of astrocytes cannot be entirely ruled out (Acaz-Fonseca et al., 2016). In addition, estradiol binds the membrane estrogen receptor $G$ proteincoupled estrogen receptor (GPR30/GPER) in astrocytes, upregulating the expression of GLT1GLT-1GLT-1 glutamate transporters, enabling an efficient glutamate uptake and avoiding glutamate derived excitotoxicity (Lee et al., 2012). Astrocytes express these receptors in a variety of brain regions, from the cortex to the hippocampus or the hypothalamus. Both the diversity of estrogen receptors and their widespread location in the brain suggest that astrocytes are important targets for the actions of estrogens in vivo, and they are essential mediators of the neuroprotective and neurotrophic effects of different estrogenic compounds in the brain.

One of the decisive factors in the triggering and extension of the neuroinflammatory response is the nuclear factor kappa-light-chain-enhancer of activated B cells (NF- $\mathrm{KB}$ ). This nuclear factor can trigger both pro- or anti-inflammatory gene transcription depending on the stimulus and cell type. NF- $\kappa$ B inhibition has been linked with the resolution of the inflammation. There are many potential targets in the NF- $\mathrm{BB}$ pathway to inhibit its activation. For instance, nonsteroidal antiinflammatory drugs (NSAIDs) inhibit NF- $\kappa \mathrm{B}$ translocation into the nucleus, and the subsequent activation of target genes, through the blockade of the IK-B kinase (IKK) enzyme activity (Yin et al., 1998). This inhibition does not allow IK-Ba phosphorylation and release from NF- $\kappa \mathrm{B}$, physically sequestering NF- $\kappa \mathrm{B}$ in the cytoplasm of the cells and keeping it inactive. Estradiol, however, has been shown to inhibit NF- $\kappa \mathrm{B}$ activity in an IKK independent way. More specifically, estradiol can inhibit p65-NF- $\mathrm{BB}$ translocation to the nucleus through the activation of PI3K (Ghisletti et al., 2005).

The anti-inflammatory effect of estradiol in astrocytes is not only driven by the direct inhibition of NF- $\kappa B$. For instance, estradiol facilitates the release of neuroprotective factors by astrocytes, such as glial cell-derived neurotrophic factor (GDNF), transforming growth factor beta (TGF- $\beta$ ), insulin-like growth factor 1 (IGF-1), nerve growth factor (NGF), BDNF, vascular endothelial growth factor (VEGF), neuroglobin and ApoE (Acaz-Fonseca et al., 2014). These factors help to maintain cell survival of the astrocytes and the surrounding cell types, and decrease cytosolic $\mathrm{Ca}^{2+}$ release from astrocytes, through a reduction in the activation signals in the area (Ricci et al., 2009).

\section{Actions of Estradiol on Oligodendrocytes} Oligodendrocytes express both ER $\alpha$ and ER $\beta$ (Khalaj et al., 2013). In addition, they also 


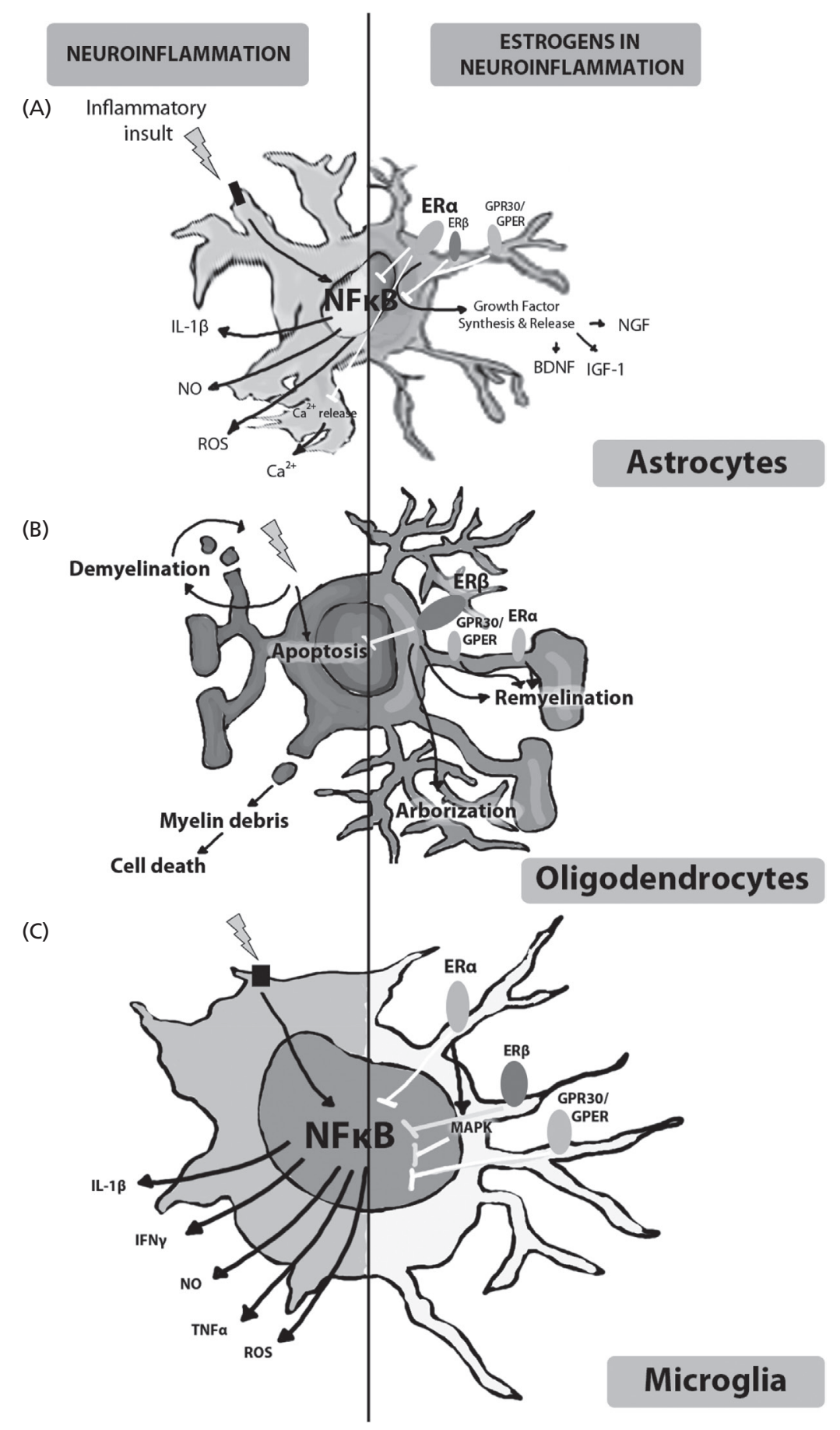

FIGURE 7.4. Cell-specific actions of estradiol to regulate neuroinflammation. Estradiol exerts a direct effect on glial cells in inflammatory conditions regulating the release of mediators and the expression of surface receptors to promote neuroprotection and restoration of neural function. (A) Inflammatory insults induce the activation of the nuclear factor kappa-light-chain-enhancer of activated B cells $(\mathrm{NF}-\kappa \mathrm{B})$ pathway, with the consequent release of pro-inflammatory mediators, such as interleukin 1 beta (IL-1 $\beta$ ), nitric oxide (NO) and reactive oxygen species (ROS), in astrocytes. Besides there is an increase in $\mathrm{Ca}^{2+}$ release by these cells and a dysregulation of their synaptic neurotransmitters uptake that eventually leads to excitotoxicity. Estradiol exerts anti-inflammatory effects in astrocytes mainly through estrogen receptor alpha (ER $)$, which inhibits NF- $\kappa \mathrm{B}$ translocation into the nucleus in 
express GPR30/GPER throughout differentiation and promyelinating stages. Specific agonists for this receptor promote remyelination by oligodendrocytes after demyelination (Hirahara, Matsuda, Yamada et al., 2013). Unlike the effects of estradiol in astrocytes, which are mediated primarily by ERa, estradiol produces antiinflammatory effects in oligodendrocytes mostly through ER $\beta$ (see Figure 7.4B).

It has been shown that estradiol prevents neuronal demyelination and oligodendrocyte cell death (Takao et al., 2004; Spence and Voskuhl, 2012). Besides, in vitro studies have shown that estradiol treatment increases OPC proliferation and has anti-apoptotic effects for mature oligodendrocytes (Marin-Husstege et al., 2004). Moreover, estradiol increases the levels of IGF-1, a survival factor that also promotes axon remyelination (Garcia-Segura and Balthazart, 2009). Estradiol also induces rapid changes in the morphology of oligodendrocytes (Hirahara, Matsuda, Yamada et al., 2013). In fact, the main ERa-mediated effect of estradiol to maintain myelin is that it induces the stabilization of actin filaments, thus avoiding neuron demyelination, through an increase in the Ras homolog gene family, member A (RhoA) activation, Rho-kinase (ROCK) stimulation and subsequent cofilin phosphorylation (Villa et al., 2016).

\section{Actions of Estradiol on Microglia}

Estradiol has well-established anti-inflammatory effects that decrease microglia activation (BruceKeller et al., 2000; see Figure 7.4C). As previously mentioned, microglia are the immune resident cells in the CNS, and the first cell type to detect and respond to any potential insult. This inflammatory response is driven by the release of proinflammatory mediators (interleukins, cytokines, chemokines, ROS, and NO), that facilitate the activation and recruitment of other cell types that will help alleviate the potential harm. However, an improper resolution of microglial activation can lead to cytotoxicity and tissue damage. Microglia activation accompanies most neurodegenerative diseases, and the modulation and resolution of this activation is an interesting therapeutic target in such cases.

Steroid hormones, such as glucocorticoids or estrogens, are well known regulators of immune responses and show anti-inflammatory properties in the CNS. Microglial cells constitutively express glucocorticoid receptor (GR), mineralocorticoid receptor (MR), ER $\alpha, E R \beta$, and GPER/GPR30 (Sierra et al., 2008; Wu et al., 2013; Chamniansawat and Chongthammakun, 2015). A proinflammatory environment, such as that found in memory and learning impairment related disorders, drastically reduces the expression of these receptors in microglial cells, suggesting that they might be implicated in the maintenance of the resting state in these cells (Chamniansawat and Chongthammakun, 2015).

Estradiol has an effective modulatory capacity in the neuroinflammatory response of microglial cells. Estradiol binding to ERa has a similar effect on astrocytes and microglia, suppressing the NF- $\kappa \mathrm{B}$ translocation to the nucleus through PI3K activation (Murphy et al., 2010). This inhibition leads to a decreased inducible NO synthase (iNOS) expression and NO release and to a reduction in ROS production by microglia (BruceKeller et al., 2000). Both NO and ROS are key for the spreading of the neuroinflammatory response; therefore, estradiol has a direct inhibitory effect in the neuroinflammatory response from early

\section{FIGURE 7.4. Continued}

a phosphatidylinositol-4,5-bisphosphate 3-kinase (PI3K)-dependent way. Activation of this receptor also inhibits the $\mathrm{Ca}^{2+}$ release by astrocytes and induces the synthesis and release of growth factors, such as nerve growth factor (NGF), insulin-like growth factor (IGF-I) and brain-derived neurotrophic factor (BDNF). Estrogen receptor beta $(\mathrm{ER} \beta)$ and $\mathrm{G}$ protein-coupled receptor 30/estrogen receptor 1 (GPR30/GPER) activation also inhibit the proinflammatory mediators release in these cells. (B) Inflammation induces apoptosis in oligodendrocytes, that is usually accompanied by demyelination and myelin debris accumulation, which enhance the pro-inflammatory response. Estradiol has direct anti-inflammatory effects on these cells mainly through ER $\beta$, inhibiting apoptosis, and promoting oligodendrocyte arborization and axon remyelination. GPR30/GPER or ERa stimulation also induce remyelination in these cells. c) In microglia, pro-inflammatory stimuli induce the activation of the NF- $\mathrm{kB}$ pathway and trigger a fast pro-inflammatory response characterized by the release of several cytokines and chemokines, such as IL-1 $\beta$, NO, ROS, tumor necrosis factor alpha (TNF $\alpha$ ) and interferon-gamma (IFN $\gamma$ ). ERa ligands decrease the proinflammatory cascade in these cells through a phosphatidylinositol-4,5-bisphosphate 3-kinase (PI3K)-dependent NF- $\mathrm{KB}$ inhibition and also through mitogen-activated protein kinase (MAPK) activation. ER $\beta$ and GPR30/GPER activation also inhibit the pro-inflammatory response in these cells. 
stages (Johann and Beyer, 2013). Estradiol also exerts ER $\alpha$-mediated anti-inflammatory effects on microglial cells through the mitogen-activated protein kinase (MAPK) pathway (Vegeto et al., 2003). Apart from the anti-inflammatory effects elicited through the ERa activation, estradiol also decreases microglial activation through GPR30/ GPER (Vegeto et al., 2003; Zhao et al., 2016) and modulates the production of microglial inflammatory mediators through the activation of $\operatorname{ER} \beta$ (Baker et al., 2004).

In addition to the modulation of neuroinflammation, estradiol regulates the phagocytic capacity of microglial cells in Alzheimer's disease transgenic mouse models, facilitating the $A \beta$ plaque clearance (Vegeto et al., 2008).

Beyond the direct effect of estradiol on $\mathrm{mi}$ croglial cells, the decrease in the release of proinflammatory mediators, such as TNFa or NO, which have a direct toxic effect on oligodendrocytes, leads to an increased survival of these cells and consequently decreases neuroinflammation-induced axon demyelination (Morales et al., 2006). Therefore, there is also an indirect effect in neuron function and survival mediated by the action of estradiol on microglia.

\section{THERAPEUTIC POTENTIAL OF ESTROGENIC COMPOUNDS FOR THE CONTROL OF \\ NEUROINFLAMMATION}

The clinical use of estradiol to promote cognition is limited by its feminizing actions and it is controversial due to its potential side effects in peripheral organs, mainly on estrogen-dependent cancer cells. An alternative to estradiol are selective estrogen receptor modulators (SERMs). SERMs readily cross the blood-brain barrier, and therefore can be systemically administered, which has a clear clinical advantage (O'Brian et al., 1985; Somjen et al., 1996). SERMs have been shown to exert procognitive effects and neuroprotective actions in a wide variety of pathological conditions in the CNS, from Alzheimer's disease or Parkinson's disease to traumatic injuries (Herrera et al., 2011; Arevalo et al., 2012; Franco Rodriguez et al., 2013; Bourque et al., 2014).

Tamoxifen and raloxifene are the most widely used SERMs for various estrogen-related diseases, including ovulatory dysfunction, breast cancer, and postmenopausal osteoporosis. Beyond their clinical use, both are potent inhibitors of neuroinflammation and to decrease reactive gliosis. Both in vitro and in brain injury in vivo models have shown that tamoxifen and raloxifene are able to reduce reactivity and inflammatory response of astrocytes and microglia (Suuronen et al., 2005; Barreto et al., 2009; Liu et al., 2010). Treatment with SERMs suppresses microglial activation and the associated proinflammatory cytokine release (Suuronen et al., 2005). This effect is mediated via an estrogen receptor-dependent pathway (Ishihara et al., 2015). The decrease in the release of inflammatory mediators, such as TNF- $\alpha$, IL- $1 \beta$, IL- 6 , or NO, leads to a reduced activation of microglia and limits neuronal cell death secondary to neuroinflammation (Liu et al., 2010; Arevalo et al., 2012; Barreto et al., 2014). Furthermore, tamoxifen and raloxifene reduce the chemotactic response to attract lymphocytes and neutrophils to the injured site, and limits immune cell proliferation, hence restricting the peripheral immune response (Rubio et al., 2011; Li et al., 2014).

Tamoxifen also has beneficial properties for oligodendrocytes in in vitro rat models. A tamoxifen-driven decrease in the production of TNF- $\alpha$ and IL- $1 \beta$ prevents injury-associated loss of myelin and has also been shown to preserve the tissue structure after injury (Ismailoglu et al., 2010; Guptarak et al., 2014). Tamoxifen has also been shown to stimulate cortical regeneration in brain injury models, at least partially due to an increase in the number of neuron-glial antigen 2 (NG2) oligodendrocyte precursors (in an ERdependent manner, at least in in vitro approaches), apart from the reduction in astrogliosis (Franco Rodriguez et al., 2013).

In addition to the indirect effect on neuronal survival through the regulation of reactive gliosis, SERMs facilitate efficient synapses through the regulation of glutamate levels in the synaptic cleft. As we have previously mentioned, many neurodegenerative diseases are associated with increased levels of glutamate in the synaptic cleft, which eventually lead to excitotoxicity and cell death. Raloxifene treatment increases the glutamate transporter expression in astrocytes (GLT-1 and GLAST), avoiding a potentially harmful glutamate accumulation (Karki et al., 2014).

Another estrogenic molecule widely used for the treatment of postmenopausal symptoms is the synthetic drug tibolone. Tibolone is metabolized in the liver into 3 main active metabolites: $3 \alpha-$ and $3 \beta-\mathrm{OH}$, which are also present in an inactive, sulphated, form, and a $\Delta 4$-metabolite, which is found in circulation. $3 a-\mathrm{OH}$-tibolone and $3 \beta-\mathrm{OH}$-tibolone activate estrogen receptors, whereas $\Delta 4$-tibolone activates progesterone and 
androgen receptors (Kloosterboer, 2001; Verheul and Kloosterboer, 2006). Interestingly, tibolone has tissue selective estrogenic actions due to the differential distribution of ERs in different organs and to its tissue-specific metabolism. Tibolone treatment has been shown to exert protective effects on glucose-deprived astrocytes, through both ER $\alpha$ and ER $\beta$, although ER $\beta$ is preferentially involved on these actions (Avila Rodriguez et al., 2014, 2016).

Apart from these synthetic estrogenic compounds, there are other natural compounds, such as phytoestrogens, that also bind to estrogen receptors (ER $\alpha, \mathrm{ER} \beta$, and GPR30). These phytochemicals are plant-derived, nonsteroidal bioactive estrogenic compounds that exert similar effects as estradiol on the control of menopausal symptoms (Chopra et al., 2016). An example is genistein. This isoflavone has anti-inflammatory effects through the decrease in the activity of NF- $\kappa \mathrm{B}$ pathway in microglia and astrocytes and the consequent attenuation in the production of proinflammatory mediators and cytokines in these cells (Lu et al., 2009; Jeong et al., 2014). It interferes with the proinflammatory activation of toll-like receptor 4 (TLR4), reducing the inflammatory damage induced by $\beta$-amyloid peptide in microglial cells (Zhou et al., 2014). As for astrocytes, genistein prevents Alzheimer's disease-associated inflammation through an increase peroxisome proliferator-activated receptors (PPAR) gamma expression, at least in in vitro studies (Valles et al., 2010). Genistein also activates some protein kinases (such as protein kinase C, PKC) that mediate oligodendrocyte progenitor proliferation (Radhakrishna and Almazan, 1994). Although genistein has some potential clinical applications, it has some disadvantages related to its chemical structure, such as rapid in vivo metabolism and a fast decline in serum after oral administration (Kwon et al., 2007).

\section{CONCLUSIONS}

The neuroprotective efficacy of estradiol has been well demonstrated in several neurodegenerative and learning-impairment related diseases. Although estradiol is known to exert several direct effects on neurons, its actions on glial cells are only beginning to be elucidated. In recent years, there has been increasing interest in the role of glial cells in the onset, progression and clinical features of neurodegenerative diseases. Astrocytes, oligodendrocytes and microglia are essential for a proper synaptic transmission and neuronal activity. Additionally, dysfunction of glial cells promotes the appearance and progression of many learning and memory deficits, such as those found in Alzheimer's disease, deficits following traumatic brain injury and in psychiatric disorders, among others, that are now being considered as glia-neuron disorders. Neuroinflammation is an important underlying component of several neurodegenerative diseases as are glial cells, which trigger and regulate this process. Appropriate resolution of neuroinflammation prevents the progressive loss of neural structure and function that leads to functional and mental impairments. Hence, the regulation of glial cell activation via estradiol and other synthetic or natural estrogenic compounds is a promising therapeutic approach to inhibit neuroinflammation, promote neuroprotection, and restore neural function.

\section{ACKNOWLEDGMENTS}

Authors acknowledge economic support from Centro de Investigación Biomédica en Red Fragilidad y Envejecimiento Saludable (CIBERFES), Spain.

\section{REFERENCES}

Acaz-Fonseca E, Avila-Rodriguez M, Garcia-Segura LM, Barreto GE (2016) Regulation of astroglia by gonadal steroid hormones under physiological and pathological conditions. Prog Neurobiol 144:5-26.

Acaz-Fonseca E, Sanchez-Gonzalez R, Azcoitia I, Arevalo MA, Garcia-Segura LM (2014) Role of astrocytes in the neuroprotective actions of 17beta-estradiol and selective estrogen receptor modulators. Mol Cell Endocrinol 389:48-57.

Ahrendsen JT, Macklin W (2013) Signaling mechanisms regulating myelination in the central nervous system. Neurosci Bull 29:199-215.

Albensi BC, Mattson MP (2000) Evidence for the involvement of TNF and NF-kappaB in hippocampal synaptic plasticity. Synapse 35:151-159.

Allen NJ (2014) Astrocyte regulation of synaptic behavior. Annu Rev Cell Dev Biol 30:439-463.

Amor S, Peferoen LA, Vogel DY, et al. (2014) Inflammation in neurodegenerative diseases-an update. Immunology 142:151-166.

Araque A, Carmignoto G, Haydon PG, Oliet SH, Robitaille R, Volterra A (2014) Gliotransmitters travel in time and space. Neuron 81:728-739.

Araque A, Navarrete M (2010) Glial cells in neuronal network function. Philos Trans R Soc Lond B Biol Sci 365:2375-2381.

Araque A, Parpura V, Sanzgiri RP, Haydon PG (1999) Tripartite synapses: glia, the unacknowledged partner. Trends Neurosci 22:208-215. 
Arevalo MA, Diz-Chaves Y, Santos-Galindo M, Bellini MJ, Garcia-Segura LM (2012) Selective oestrogen receptor modulators decrease the inflammatory response of glial cells. J Neuroendocrinol 24:183-190.

Arnold JT, Le H, McFann KK, Blackman MR (2005) Comparative effects of DHEA vs. testosterone, dihydrotestosterone, and estradiol on proliferation and gene expression in human LNCaP prostate cancer cells. Am J Physiol Endocrinol Metab 288:E573-E584.

Attwell D, Buchan AM, Charpak S, Lauritzen M, Macvicar BA, Newman EA (2010) Glial and neuronal control of brain blood flow. Nature 468:232-243.

Avila Rodriguez M, Garcia-Segura LM, Cabezas R, et al. (2014) Tibolone protects T98G cells from glucose deprivation. J Steroid Biochem Mol Biol 144(Pt B):294-303.

Avila-Rodriguez M, Garcia-Segura LM, HidalgoLanussa O, Baez E, Gonzalez J, Barreto GE (2016) Tibolone protects astrocytic cells from glucose deprivation through a mechanism involving estrogen receptor beta and the upregulation of neuroglobin expression. Mol Cell Endocrinol 433:35-46.

Axtell RC, Steinman L (2009) Gaining entry to an uninflamed brain. Nat Immunol 10:453-455.

Baker AE, Brautigam VM, Watters JJ (2004) Estrogen modulates microglial inflammatory mediator production via interactions with estrogen receptor beta. Endocrinology 145:5021-5032.

Barres BA (2008) The mystery and magic of glia: a perspective on their roles in health and disease. Neuron 60:430-440.

Barreto G, Santos-Galindo M, Diz-Chaves Y, et al. (2009) Selective estrogen receptor modulators decrease reactive astrogliosis in the injured brain: effects of aging and prolonged depletion of ovarian hormones. Endocrinology 150:5010-5015.

Barreto GE, Santos-Galindo M, Garcia-Segura LM (2014) Selective estrogen receptor modulators regulate reactive microglia after penetrating brain injury. Front Aging Neurosci 6:132.

Bazargani N, Attwell D (2016) Astrocyte calcium signaling: the third wave. Nat Neurosci 19:182-189.

Beattie EC, Stellwagen D, Morishita W, et al. (2002) Control of synaptic strength by glial TNFalpha. Science 295:2282-2285.

Bernardinelli Y, Muller D, Nikonenko I (2014) Astrocyte-synapse structural plasticity. Neural Plast 2014:232105.

Bourque M, Morissette M, Di Paolo T (2014) Raloxifene activates $\mathrm{G}$ protein-coupled estrogen receptor 1/ Akt signaling to protect dopamine neurons in 1methyl-4-phenyl-1,2,3,6-tetrahydropyridine mice. Neurobiol Aging 35:2347-2356.

Bruce-Keller AJ, Keeling JL, Keller JN, Huang FF, Camondola S, Mattson MP (2000)
Antiinflammatory effects of estrogen on microglial activation. Endocrinology 141:3646-3656.

Burda JE, Sofroniew MV (2014) Reactive gliosis and the multicellular response to CNS damage and disease. Neuron 81:229-248.

Burton MD, Johnson RW (2012) Interleukin-6 transsignaling in the senescent mouse brain is involved in infection-related deficits in contextual fear conditioning. Brain Behav Immun 26:732-738.

Caroni P, Donato F, Muller D (2012) Structural plasticity upon learning: regulation and functions. Nat Rev Neurosci 13:478-490.

Chaban VV, Lakhter AJ, Micevych P (2004) A membrane estrogen receptor mediates intracellular calcium release in astrocytes. Endocrinology 145:3788-3795.

Chamniansawat S, Chongthammakun S (2015) Inhibition of hippocampal estrogen synthesis by reactive microglia leads to down-regulation of synaptic protein expression. Neurotoxicology 46:25-34.

Chen WW, Zhang X, Huang WJ (2016) Role of neuroinflammation in neurodegenerative diseases (Review). Mol Med Rep 13:3391-3396.

Chopra K, Bansal S, Sachdeva AK (2016) Phytochemicals: potential in management of climacteric neurobiology. Curr Pharm Des 22:4098-4110.

Chung WS, Allen NJ, Eroglu C (2015) Astrocytes control synapse formation, function, and elimination. Cold Spring Harb Perspect Biol 7:a020370.

Czerniawski J, Guzowski JF (2014) Acute neuroinflammation impairs context discrimination memory and disrupts pattern separation processes in hippocampus. J Neurosci 34:12470-12480.

D’Agostino PM, Gottfried-Blackmore A, Anandasabapathy N, Bulloch K (2012) Brain dendritic cells: biology and pathology. Acta Neuropathol 124:599-614.

Dantzer R, O'Connor JC, Freund GG, Johnson RW, Kelley KW (2008) From inflammation to sickness and depression: when the immune system subjugates the brain. Nat Rev Neurosci 9:46-56.

D'Arcangelo G, Tancredi V, Onofri F, D'Antuono M, Giovedi S, Benfenati F (2000) Interleukin-6 inhibits neurotransmitter release and the spread of excitation in the rat cerebral cortex. Eur J Neurosci 12:1241-1252.

De Biase LM, Nishiyama A, Bergles DE (2010) Excitability and synaptic communication within the oligodendrocyte lineage. J Neurosci 30:3600-3611.

Engelhardt B, Carare RO, Bechmann I, Flugel A, Laman JD, Weller RO (2016) Vascular, glial, and lymphatic immune gateways of the central nervous system. Acta Neuropathol 132:317-338.

Eroglu C, Barres BA (2010) Regulation of synaptic connectivity by glia. Nature $468: 223-231$. 
Fields RD, Araque A, Johansen-Berg $\mathrm{H}$, et al. (2014) Glial biology in learning and cognition. Neuroscientist 20:426-431.

Fields RD, Stevens-Graham B (2002) New insights into neuron-glia communication. Science 298:556-562.

Fields RD, Woo DH, Basser PJ (2015) Glial regulation of the neuronal connectome through local and long-distant communication. Neuron 86:374-386.

Fonseca MI, Zhou J, Botto M, Tenner AJ (2004) Absence of $\mathrm{C} 1 \mathrm{q}$ leads to less neuropathology in transgenic mouse models of Alzheimer's disease. J Neurosci 24:6457-6465.

Franco Rodriguez NE, Duenas Jimenez JM, De la Torre Valdovinos B, et al. (2013) Tamoxifen favoured the rat sensorial cortex regeneration after a penetrating brain injury. Brain Res Bull 98:64-75.

Garcia-Ovejero D, Azcoitia I, DonCarlos LL, Melcangi RC, Garcia-Segura LM (2005) Glia-neuron crosstalk in the neuroprotective mechanisms of sex steroid hormones. Brain Res Brain Res Rev 48:273-286.

Garcia-Segura LM, Balthazart J (2009) Steroids and neuroprotection: new advances. Front Neuroendocrinol 30:v-ix.

Garcia-Segura LM, Wozniak A, Azcoitia I, Rodriguez JR, Hutchison RE, Hutchison JB (1999) Aromatase expression by astrocytes after brain injury: implications for local estrogen formation in brain repair. Neuroscience 89:567-578.

Ghisletti S, Meda C, Maggi A, Vegeto E (2005) 17betaestradiol inhibits inflammatory gene expression by controlling NF-kappaB intracellular localization. Mol Cell Biol 25:2957-2968.

Ginhoux F, Prinz M (2015) Origin of microglia: current concepts and past controversies. Cold Spring Harb Perspect Biol 7:a020537.

Glass CK, Saijo K, Winner B, Marchetto MC, Gage FH (2010) Mechanisms underlying inflammation in neurodegeneration. Cell 140:918-934.

Gomez-Nicola D, Perry VH (2015) Microglial dynamics and role in the healthy and diseased brain: a paradigm of functional plasticity. Neuroscientist 21:169-184.

Groszer M, et al. (2008) Impaired synaptic plasticity and motor learning in mice with a point mutation implicated in human speech deficits. Curr Biol 18:354-362.

Guerreiro RJ, Santana I, Bras JM, Santiago B, Paiva A, Oliveira C (2007) Peripheral inflammatory cytokines as biomarkers in Alzheimer's disease and mild cognitive impairment. Neurodegener Dis 4:406-412.

Guptarak J, Wiktorowicz JE, Sadygov RG, et al. (2014) The cancer drug tamoxifen: a potential therapeutic treatment for spinal cord injury. J Neurotrauma 31:268-283.

Haber M, Zhou L, Murai KK (2006) Cooperative astrocyte and dendritic spine dynamics at hippocampal excitatory synapses. J Neurosci 26:8881-8891.
Halassa MM, Fellin T, Haydon PG (2007) The tripartite synapse: roles for gliotransmission in health and disease. Trends Mol Med 13:54-63.

Halassa MM, Haydon PG (2010) Integrated brain circuits: astrocytic networks modulate neuronal activity and behavior. Annu Rev Physiol 72:335-355.

Harry GJ, Kraft AD (2008) Neuroinflammation and microglia: considerations and approaches for neurotoxicity assessment. Expert Opin Drug Metab Toxicol 4:1265-1277.

Heppner FL, Ransohoff RM, Becher B (2015) Immune attack: the role of inflammation in Alzheimer disease. Nat Rev Neurosci 16:358-372.

Herrera JL, Fernandez C, Diaz M, Cury D, Marin R (2011) Estradiol and tamoxifen differentially regulate a plasmalemmal voltage-dependent anion channel involved in amyloid-beta induced neurotoxicity. Steroids 76:840-844.

Hirahara Y, Matsuda KI, Liu YF, Yamada H, Kawata M, Boggs JM (2013) 17beta-Estradiol and 17alphaestradiol induce rapid changes in cytoskeletal organization in cultured oligodendrocytes. Neuroscience 235:187-199.

Hirahara Y, Matsuda KI, Yamada H, et al. (2013) $\mathrm{G}$ protein-coupled receptor 30 contributes to improved remyelination after cuprizone-induced demyelination. Glia 61:420-431.

Holmes GL (2001) Pathogenesis of learning disabilities in epilepsy. Epilepsia 42(Suppl 1):1315; discussion 19-20.

Huijbregts SC, Kalkers NF, de Sonneville LM, de Groot V, Reuling IE, Polman CH (2004) Differences in cognitive impairment of relapsing remitting, secondary, and primary progressive MS. Neurology 63:335-339.

Irwin MR (2011) Inflammation at the intersection of behavior and somatic symptoms. Psychiatr Clin North Am 34:605-620.

Ishihara Y, Itoh K, Ishida A, Yamazaki T (2015) Selective estrogen-receptor modulators suppress microglial activation and neuronal cell death via an estrogen receptor-dependent pathway. J Steroid Biochem Mol Biol 145:85-93.

Ishizawa K, Dickson DW (2001) Microglial activation parallels system degeneration in progressive supranuclear palsy and corticobasal degeneration. J Neuropathol Exp Neurol 60:647-657.

Ismailoglu O, Oral B, Gorgulu A, Sutcu R, Demir N (2010) Neuroprotective effects of tamoxifen on experimental spinal cord injury in rats. J Clin Neurosci 17:1306-1310.

Jeong JW, Lee HH, Han MH, Kim GY, Kim WJ, Choi YH (2014) Anti-inflammatory effects of genistein via suppression of the toll-like receptor 4-mediated signaling pathway in lipopolysaccharide-stimulated BV2 microglia. Chem Biol Interact 212:30-39.

Ji K, Miyauchi J, Tsirka SE (2013) Microglia: an active player in the regulation of synaptic activity. Neural Plast 2013:627325. 
Johann S, Beyer C (2013) Neuroprotection by gonadal steroid hormones in acute brain damage requires cooperation with astroglia and microglia. J Steroid Biochem Mol Biol 137:71-81.

Karki P, Webb A, Zerguine A, Choi J, Son DS, Lee E (2014) Mechanism of raloxifene-induced upregulation of glutamate transporters in rat primary astrocytes. Glia 62:1270-1283.

Kettenmann H, Hanisch UK, Noda M, Verkhratsky A (2011) Physiology of microglia. Physiol Rev 91:461-553.

Kettenmann H, Kirchhoff F, Verkhratsky A (2013) Microglia: new roles for the synaptic stripper. Neuron 77:10-18.

Khalaj AJ, Yoon J, Nakai J, et al. (2013) Estrogen receptor (ER) beta expression in oligodendrocytes is required for attenuation of clinical disease by an ERbeta ligand. Proc Natl Acad Sci USA 110:19125-19130.

Kloosterboer HJ (2001) Tibolone: a steroid with a tissue-specific mode of action. J Steroid Biochem Mol Biol 76:231-238.

Kolodziejczyk K, Saab AS, Nave KA, Attwell D (2010) Why do oligodendrocyte lineage cells express glutamate receptors? F1000 Biol Rep 2:57.

Kriegstein A, Alvarez-Buylla A (2009) The glial nature of embryonic and adult neural stem cells. Annu Rev Neurosci 32:149-184.

Kwon SH, Kang MJ, Huh JS, et al. (2007) Comparison of oral bioavailability of genistein and genistin in rats. Int J Pharm 337:148-154.

Lampron A, Elali A, Rivest S (2013) Innate immunity in the CNS: redefining the relationship between the CNS and Its environment. Neuron 78:214-232.

Lee E, Sidoryk-Wegrzynowicz M, Wang N, et al. (2012) GPR30 regulates glutamate transporter GLT-1 expression in rat primary astrocytes. J Biol Chem 287:26817-26828.

Leong SY, Rao VT, Bin JM, et al. (2014) Heterogeneity of oligodendrocyte progenitor cells in adult human brain. Ann Clin Transl Neurol 1:272-283.

Lepeta K, Lourenco MV, Schweitzer BC, et al. (2016) Synaptopathies: synaptic dysfunction in neurological disorders-A review from students to students. J Neurochem 138:785-805.

Li R, Xu W, Chen Y, et al. (2014) Raloxifene suppresses experimental autoimmune encephalomyelitis and NF-kappaB-dependent CCL20 expression in reactive astrocytes. PLoS One 9:e94320.

Lichtman JW, Colman H (2000) Synapse elimination and indelible memory. Neuron 25:269-278.

Liu JJ, Green P, Mann J, Rapoport SI, Sublette ME (2015) Pathways of polyunsaturated fatty acid utilization: implications for brain function in neuropsychiatric health and disease. Brain Res 1597:220-246.

Liu JL, Tian DS, Li ZW, et al. (2010) Tamoxifen alleviates irradiation-induced brain injury by attenuating microglial inflammatory response in vitro and in vivo. Brain Res 1316:101-111.

Lu H, Shi JX, Zhang DM, et al. (2009) Inhibition of hemolysate-induced iNOS and COX-2 expression by genistein through suppression of NF-small ka, CyrillicB activation in primary astrocytes. J Neurol Sci 278:91-95.

Madeira C, Lourenco MV, Vargas-Lopes C, et al. (2015) d-serine levels in Alzheimer's disease: implications for novel biomarker development. Transl Psychiatry 5:e561.

Majerova P, Zilkova M, Kazmerova Z, et al. (2014) Microglia display modest phagocytic capacity for extracellular tau oligomers. J Neuroinflammation 11:161.

Maragakis NJ, Rothstein JD (2006) Mechanisms of disease: astrocytes in neurodegenerative disease. Nat Clin Pract Neurol 2:679-689.

Marin-Husstege M, Muggironi M, Raban D, Skoff RP, Casaccia-Bonnefil P (2004) Oligodendrocyte progenitor proliferation and maturation is differentially regulated by male and female sex steroid hormones. Dev Neurosci 26:245-254.

Martineau M, Parpura V, Mothet JP (2014) Cell-type specific mechanisms of D-serine uptake and release in the brain. Front Synaptic Neurosci 6:12.

McKim DB, Niraula A, Tarr AJ, Wohleb ES, Sheridan JF, Godbout JP (2016) Neuroinflammatory dynamics underlie memory impairments after repeated social defeat. J Neurosci 36:2590-2604.

Micevych P, Bondar G, Kuo J (2010) Estrogen actions on neuroendocrine glia. Neuroendocrinology 91:211-222.

Michalski JP, Kothary R (2015) Oligodendrocytes in a nutshell. Front Cell Neurosci 9:340.

Mitew S, Hay CM, Peckham H, Xiao J, Koenning M, Emery B (2014) Mechanisms regulating the development of oligodendrocytes and central nervous system myelin. Neuroscience 276:29-47.

Morales LB, Loo KK, Liu HB, et al. (2006) Treatment with an estrogen receptor alpha ligand is neuroprotective in experimental autoimmune encephalomyelitis. J Neurosci 26:6823-6833.

Morrison JH, Baxter MG (2012) The ageing cortical synapse: hallmarks and implications for cognitive decline. Nat Rev Neurosci 13:240-250.

Murphy AJ, Guyre PM, Pioli PA (2010) Estradiol suppresses NF-kappa B activation through coordinated regulation of let-7a and miR-125b in primary human macrophages. J Immunol 184:5029-5037.

Neumann H, Kotter MR, Franklin RJ (2009) Debris clearance by microglia: an essential link between degeneration and regeneration. Brain 132:288-295.

Norden DM, Trojanowski PJ, Villanueva E, Navarro E, Godbout JP (2016) Sequential activation of microglia and astrocyte cytokine expression precedes increased Iba-1 or GFAP immunoreactivity 
following systemic immune challenge. Glia 64:300-316.

Ober C, Loisel DA, Gilad Y (2008) Sex-specific genetic architecture of human disease. Nat Rev Genet 9:911-922.

Oberheim NA, Wang X, Goldman S, Nedergaard M (2006) Astrocytic complexity distinguishes the human brain. Trends Neurosci 29:547-553.

O'Brian CA, Liskamp RM, Solomon DH, Weinstein IB (1985) Inhibition of protein kinase C by tamoxifen. Cancer Res 45:2462-2465.

O'Connor JJ, Coogan AN (1999) Actions of the proinflammatory cytokine IL-1 beta on central synaptic transmission. Exp Physiol 84:601-614.

Perry VH, O'Connor V (2008) C1q: the perfect complement for a synaptic feast? Nat Rev Neurosci 9:807-811.

Pugh CR, Kumagawa K, Fleshner M, Watkins LR, Maier SF, Rudy JW (1998) Selective effects of peripheral lipopolysaccharide administration on contextual and auditory-cue fear conditioning. Brain Behav Immun 12:212-229.

Radhakrishna M, Almazan G (1994) Protein kinases mediate basic fibroblast growth factor's stimulation of proliferation and c-fos induction in oligodendrocyte progenitors. Brain Res Mol Brain Res 24:118-128.

Ramesh G, MacLean AG, Philipp MT (2013) Cytokines and chemokines at the crossroads of neuroinflammation, neurodegeneration, and neuropathic pain. Mediators Inflamm 2013:480739.

Ransohoff RM, Brown MA (2012) Innate immunity in the central nervous system. J Clin Invest 122:1164-1171.

Ricci G, Volpi L, Pasquali L, Petrozzi L, Siciliano G (2009) Astrocyte-neuron interactions in neurological disorders. J Biol Phys 35:317-336.

Risher WC, Eroglu C (2012) Thrombospondins as key regulators of synaptogenesis in the central nervous system. Matrix Biol 31:170-177.

Rogers J, Mastroeni D, Leonard B, Joyce J, Grover A (2007) Neuroinflammation in Alzheimer's disease and Parkinson's disease: are microglia pathogenic in either disorder? Int Rev Neurobiol 82:235-246.

Rossner S, Lange-Dohna C, Zeitschel U, Perez-Polo JR (2005) Alzheimer's disease beta-secretase BACE1 is not a neuron-specific enzyme. J Neurochem 92:226-234.

Roth AD, Ramirez G, Alarcon R, Von Bernhardi R (2005) Oligodendrocytes damage in Alzheimer's disease: beta amyloid toxicity and inflammation. Biol Res 38:381-387.

Rubio N, Cerciat M, Unkila M, Garcia-Segura LM, Arevalo MA (2011) An in vitro experimental model of neuroinflammation: the induction of interleukin-6 in murine astrocytes infected with Theiler's murine encephalomyelitis virus, and its inhibition by oestrogenic receptor modulators. Immunology 133:360-369.
Saldanha CJ, Duncan KA, Walters BJ (2009) Neuroprotective actions of brain aromatase. Front Neuroendocrinol 30:106-118.

Salmina AB (2009) Neuron-glia interactions as therapeutic targets in neurodegeneration. J Alzheimers Dis 16:485-502.

Scemes E, Giaume C (2006) Astrocyte calcium waves: what they are and what they do. Glia 54:716-725.

Schafer DP, Lehrman EK, Kautzman AG, et al. (2012) Microglia sculpt postnatal neural circuits in an activity and complement-dependent manner. Neuron 74:691-705.

Schousboe A, Scafidi S, Bak LK, Waagepetersen HS, McKenna MC (2014) Glutamate metabolism in the brain focusing on astrocytes. Adv Neurobiol 11:13-30.

Shaw KN, Commins S, O’Mara SM (2001) Lipopolysaccharide causes deficits in spatial learning in the watermaze but not in BDNF expression in the rat dentate gyrus. Behav Brain Res 124:47-54.

Sie C, Korn T (2017) Dendritic cells in central nervous system autoimmunity. Semin Immunopathol 39:99-111.

Sierra A, Encinas JM, Deudero JJ, et al. (2010) Microglia shape adult hippocampal neurogenesis through apoptosis-coupled phagocytosis. Cell Stem Cell 7:483-495.

Sierra A, Gottfried-Blackmore A, Milner TA, McEwen BS, Bulloch K (2008) Steroid hormone receptor expression and function in microglia. Glia 56:659-674.

Simons M, Misgeld T, Kerschensteiner M (2014) A unified cell biological perspective on axon-myelin injury. J Cell Biol 206:335-345.

Sofroniew MV, Vinters HV (2010) Astrocytes: biology and pathology. Acta Neuropathol 119:7-35.

Somjen D, Waisman A, Kaye AM (1996) Tissue selective action of tamoxifen methiodide, raloxifene and tamoxifen on creatine kinase B activity in vitro and in vivo. J Steroid Biochem Mol Biol 59:389-396.

Sparkman NL, Johnson RW (2008) Neuroinflammation associated with aging sensitizes the brain to the effects of infection or stress. Neuroimmunomodulation 15:323-330.

Spence RD, Voskuhl RR (2012) Neuroprotective effects of estrogens and androgens in CNS inflammation and neurodegeneration. Front Neuroendocrinol 33:105-115.

Spence RD, Wisdom AJ, Cao Y, et al. (2013) Estrogen mediates neuroprotection and anti-inflammatory effects during EAE through ERalpha signaling on astrocytes but not through ERbeta signaling on astrocytes or neurons. J Neurosci 33:10924-10933.

Stephan AH, Barres BA, Stevens B (2012) The complement system: an unexpected role in synaptic pruning during development and disease. Annu Rev Neurosci 35:369-389. 
Stevens B, Allen NJ, Vazquez LE, et al. (2007) The classical complement cascade mediates CNS synapse elimination. Cell 131:1164-1178.

Stiles J, Jernigan TL (2010) The basics of brain development. Neuropsychol Rev 20:327-348.

Straub RH (2007) The complex role of estrogens in inflammation. Endocr Rev 28:521-574.

Suuronen T, Nuutinen T, Huuskonen J, et al. (2005) Anti-inflammatory effect of selective estrogen receptor modulators (SERMs) in microglial cells. Inflamm Res 54:194-203.

Takao T, Flint N, Lee L, et al. (2004) 17beta-estradiol protects oligodendrocytes from cytotoxicity induced cell death. J Neurochem 89:660-673.

Takeuchi H, Jin S, Wang J, et al. (2006) Tumor necrosis factor-alpha induces neurotoxicity via glutamate release from hemichannels of activated microglia in an autocrine manner. J Biol Chem 281:21362-21368.

Tauheed AM, Ayo JO, Kawu MU (2016) Regulation of oligodendrocyte differentiation: insights and approaches for the management of neurodegenerative disease. Pathophysiology.

Taveggia C, Feltri ML, Wrabetz L (2010) Signals to promote myelin formation and repair. Nat Rev Neurol 6:276-287.

Tay TL, Savage J, Hui CW, Bisht K, Tremblay ME (2016) Microglia across the lifespan: from origin to function in brain development, plasticity and cognition. J Physiol.

Valles SL, Dolz-Gaiton P, Gambini J, et al. (2010) Estradiol or genistein prevent Alzheimer's diseaseassociated inflammation correlating with an increase PPAR gamma expression in cultured astrocytes. Brain Res 1312:138-144.

Vegeto E, Belcredito S, Etteri S, et al. (2003) Estrogen receptor-alpha mediates the brain antiinflammatory activity of estradiol. Proc Natl Acad Sci USA 100:9614-9619.

Vegeto E, Benedusi V, Maggi A (2008) Estrogen antiinflammatory activity in brain: a therapeutic opportunity for menopause and neurodegenerative diseases. Front Neuroendocrinol 29:507-519.

Verheul HA, Kloosterboer HJ (2006) Metabolism of exogenous sex steroids and effect on brain functions with a focus on tibolone. J Steroid Biochem Mol Biol 102:195-204.
Villa A, Vegeto E, Poletti A, Maggi A (2016) Estrogens, neuroinflammation, and neurodegeneration. Endocr Rev 37:372-402.

Wang H, Liu H, Zhang ZW (2011) Elimination of redundant synaptic inputs in the absence of synaptic strengthening. J Neurosci 31:16675-16684.

Wright CL, Schwarz JS, Dean SL, McCarthy MM (2010) Cellular mechanisms of estradiol-mediated sexual differentiation of the brain. Trends Endocrinol Metab 21:553-561.

Wu WF, Tan XJ, Dai YB, et al. (2013) Targeting estrogen receptor beta in microglia and $\mathrm{T}$ cells to treat experimental autoimmune encephalomyelitis. Proc Natl Acad Sci USA 110: 3543-3548.

Wu Y, Dissing-Olesen L, MacVicar BA, Stevens B (2015) Microglia: dynamic mediators of synapse development and plasticity. Trends Immunol 36:605-613.

Xanthos DN, Sandkuhler J (2014) Neurogenic neuroinflammation: inflammatory CNS reactions in response to neuronal activity. Nat Rev Neurosci 15:43-53.

Xavier AL, Menezes JR, Goldman SA, Nedergaard M (2014) Fine-tuning the central nervous system: microglial modelling of cells and synapses. Philos Trans R Soc Lond B Biol Sci 369:20130593.

Yaffe K, Lindquist K, Penninx BW, et al. (2003) Inflammatory markers and cognition in wellfunctioning African-American and white elders. Neurology 61:76-80.

Yagi H, Sato M (2008) Control of neural cell migration during the development of the central nervous system. Brain Nerve 60:383-394.

Yin MJ, Yamamoto Y, Gaynor RB (1998) The antiinflammatory agents aspirin and salicylate inhibit the activity of I(kappa)B kinase-beta. Nature 396:77-80.

Zhao TZ, Ding Q, Hu J, et al. (2016) GPER expressed on microglia mediates the anti-inflammatory effect of estradiol in ischemic stroke. Brain Behav 6:e00449.

Zhou X, Yuan L, Zhao X, et al. (2014) Genistein antagonizes inflammatory damage induced by beta-amyloid peptide in microglia through TLR4 and NF-kappaB. Nutrition 30:90-95. 